\title{
CONFLITO DISCURSIVO NAS HERÓIDES DE OVÍDIO
}

\author{
CLEONICE FURTADO DE MENDONÇA VAN RAIJ* \\ Pontifícia Universidade Católica de Campinas
}

\begin{abstract}
RESUMO: Este artigo objetiva analisar, nas Heróides, o conflito discursivo entre o individual e o universal, revelando como a autora de cada carta manifesta, por meio de um monólogo interior, seu mundo pessoal, numa dimensão totalmente diferente do modelo psicológico que representa.
\end{abstract}

PALAVRAS-CHAVE: Ovídio; Heróides; conflito discurso.

Escritas no gênero epistolar, muito em voga na época de Augusto (43 a.C. -14 d.C.), as Heróides constituem, entre os trabalhos de elegia, a única coleção de cartas oriunda da antigüidade greco-romana que resistiu ao tempo. Entretanto, inúmeros estudiosos contestam tal ponto de vista. Renney, citado por Knox (1955, p. 14), sustenta, contudo, não haver qualquer razão para que se acredite ter algum poeta, grego ou romano, anterior a Ovídio, escrito cartas semelhantes às Heróides.

Vale salientar que, quando o poeta compôs suas Cartas, já existiam textos literários em forma de carta. Lucílio (108-103 a.C.) é um exemplo, mas, não obstante ter composto obra nessa forma, o fez no gênero satírico, perpassado por tom filosófico; cite-se, também, Propércio (45 ?-16 ? d.C.), cuja elegia IV, 3 é constituída por uma carta de Aretusa a Licotas, que se ausentara de Roma. Dissimulando ambos personagens reais.

Diverso é o procedimento de Ovídio: dando às suas Heróides forma elegíaca, afasta-se de Lucílio, distanciando-se também de Propércio, na medida em que coloca personagens mitológicas em situação de diálogo.

As Heróides - cartas escritas por quatorze mulheres da mitologia clássica e uma da literatura grega (Safo) para seus amantes, namorados ou maridos, ausentes por inúmeras razões - são compostas de elementos tomados de gêneros considerados maiores - epopéia e tragédia -, e também de ingredientes de outras tradições literárias (epigrama , poesia bucólica, narrativa erótica, retórica. A fusão acaba por dar origem a uma 
forma absolutamente diferente daquela já existente na elegia amorosa latina. Fedra (IV), por exemplo, ao confessar seu interesse pela caça, registra, em sua carta, não só uma característica da antiga elegia romana, mas ainda a reconstituição de um monólogo dramático do Hipólito (Eurípides), argumento com que procura conquistar o belo enteado, desinteressado e virgem.

É notória, na constituição das Cartas, a justaposição do elemento épico (ainda que tratem de um drama pessoal, por trás de muitas delas há um cenário épico: a guerra de Tróia) ao mundo elegíaco (as heroínas ovidianas retratam as mulheres da elegia romana, que revela, segundo Della Casa (1981, p. XIII), o amor com um tríplice caráter:

i) erótico / mundano;

ii) ideal de vida;

iii) um mal, uma doença incurável, um sofrimento desesperador.

Não se pode ignorar a influência significativa que exerceram sobre as Heróides os exercícios literários realizados nas escolas de retores, freqüentadas por Ovídio na sua adolescência, o que acabou por fazer com que a linguagem das Cartas, embora clara e harmoniosa, se tornasse um tanto artificial. Autores há, e não são poucos, que defendem a posição de terem as Heróides seu conteúdo e estrutura moldados na suasória, exercício por meio do qual a personagem se vale da palavra para resolver seus problemas. Neste caso, as heroínas ovidianas, confrontadas continuamente com a dor, tentam convencer o amante distante a regressar. Há aqueles que consideram que as Cartas revelam afinidades maiores com o monólogo dramático do que com a suasória, sem que apontem, todavia, as implicações decorrentes de tal diferença. Outros declaram que as Heróides carecem de um contexto dramático e narrativo: não há nas Cartas um confronto de emoções e aspirações de duas pessoas que se amam ou que estão em conflito, nem tampouco um jogo de tempo, o que descarta, seguramente, um envolvimento com o futuro, razão por que o poema é considerado de natureza estática ou uma repetição monótona de queixas e de dores que envolvem o mundo da mulher ovidiana.

A carência de tensão e conflito dramático apontada é, no entanto, ricamente compensada por tensão e conflito existentes em outra esfera. Para Brownlee (1980, p. 8), na medida em que promove como que um "casamento" entre o discurso mítico e o gênero epistolar, Ovídio explicita um conflito entre o individual e o universal: a autora de cada carta trabalha um determinado mito em todo seu envolvimento existencial. Mulheres lendárias ou históricas (Safo) manifestam sua própria interpretação subjetiva 
do mito a que pertencem: por meio de um monólogo interior, retratam seu mundo pessoal, dimensão totalmente diferente do modelo psicológico que representam. Pelo retrato de cada uma é possível vislumbrar, num primeiro plano, um aspecto desse amor lendário, que difere daquele que vivem como criaturas do mito. Assim, cada heroína a seu modo apresenta, a princípio, uma postura mítica por ações notáveis que logram realizar: Penélope e Laodamia, por sua fidelidade a Ulisses e Protesilau; Fedra, por seu incesto; Medéia e Hipsípile, por suas magias, violências e vinganças; Ariadne, pelo abandono de Teseu, depois de tê-lo ajudado a livrar-se do labirinto; Dido , por seu poder, carisma e desespero final; Safo, por sua ousadia e cruel amor a Fáon, e assim por diante. Posteriormente, essas mulheres são vistas também, sob outra ótica, graças ao monólogo interior a que dão lugar, quando em função da solidão em que vivem.

As heroinas ovidianas são todas, inegavelmente, mulheres de significativa e lendária postura: encarnações de intensos e freqüentes momentos literários trágicos do passado.

Todavia, segundo Verducci (1990, p. 80-81), “apesar de os 'modelos' ovidianos serem bastante conhecidos, o poeta romano distancia as heroínas de suas bases literárias, dotando-as de características um tanto humanas: todas se revelam incapazes, falíveis, frágeis, a ponto de os assuntos dos quais tratam (originários da tragédia e da épica) e também a personificação tornarem-se para elas questões de sentimento e perspectivas momentâneas, e não normas e valores universais e permanentes".

Ovídio subverte, assim, o mito, provocando um deslocamento das heroínas mitológicas e revelando-as na sua natureza humana: mulheres tomadas por uma paixão avassaladora, que as destrói e as envolve num mundo de desilusão, loucura, obsessão e, muitas vezes, de banalidade.

Surge, assim, uma mulher mitológica inteiramente nova, colocada na primeira pessoa para falar ao amor distante e revelar-lhe sentimentos que derivam do conflito nascido de suas aspirações femininas e da realidade insensível de um mundo masculino, uma vez que, ao longo das Cartas, as heroínas oscilam entre paixão e razão; amor e ódio; prazer e dor; repulsa e procura; ousadia e medo; pensamento de autodestruição e devaneios amorosos; desespero e renovadas esperanças. Os limites desses sentimentos, já frágeis por natureza, se "esgarçam" cada vez mais, em razão do momento difícil por que elas passam. A freqüência com que se interpenetram acentua o caráter ambíguo, frágil, inseguro da mulher ovidiana. $\mathrm{O}$ uso do discurso direto é decisivo, categórico mesmo. É ele que vai, determinantemente, diferenciar o discurso narrativo (característico da mitologia) do mundo real que evoca. Valendo-se dele, a autora de cada carta logra controle absoluto sobre o próprio discurso. Subjuga-o, por assim dizer, tornando- 
se, então, dona de sua fala, podendo falar, declarar-se, mostrar-se infeliz, desajustada, solitária.

Ao expor os tormentos subjetivos de figuras lendárias em justaposição com um escritor subjacente, que escreve na primeira pessoa e se proclama vítima do abandono, Ovídio estabelece, em suas Cartas, segundo Brownlee (1990, p. 27), uma espécie de discurso novelístico, de cuja variedade as Heróides, no entender de Bakhtin (1984), representam uma ilustração significativa.

Bakhtin contrapõe ao monologismo da épica e do romance o dialogismo da novela, "gênero em que o discurso literário idealizado se enfraquece, quando em contato com os discursos não-literários e não-heróicos da realidade quotidiana” (1984, p. 4).

O procedimento ovidiano é inteiramente original, como afirma Brownlee (1990, p. 7): "a anatomia do amor arraigado na primeira pessoa encontra sua origem nas Heróides de Ovídio".

Não obstante essa transformação sofrida pelas heroínas mitológicas, não se verifica uma desvalorização do mito heróico, como declara Jacobson (1974, p. 354): "O tratamento de Ovídio não denigre o mito heróico. De certo modo, dá-se a sua elevação, ou melhor, a sua interpretação numa dimensão complementar diferente".

Assim, acerca da natureza das Heróides, registre-se o pensamento de Danielle Porte (1993, p. 78): "A 'pérola' do gênero epistolar é, sem dúvida, a coleção das Heróides, tarefa difícil a que Ovídio se propôs ao escrever vinte e uma cartas de uma só vez. É claro que Safo não escrevera como Medéia, nem Penélope como Dejanira, mas o ponto de partida é idêntico: vinte e uma heroínas míticas escrevem a um sedutor que se foi. Em seu todo, nenhuma é inteiramente igual".

As Cartas, segundo Gaillard (1992, p. 111), "de tempo indefinido/vazio e de espaço simbolicamente construído, reduzem a dor a uma atitude e amplificam o discurso amoroso como gesto".

Num discurso que oscila entre o fabuloso e o real, Ovídio delineia a paixão, expondo desilusões, insensatez, desencontros, obsessões e contradições de suas heroínas, que, no entanto, raramente se privam da simpatia do poeta romano, o qual acaba retratando a vida delas "com o mais elevado e refinado sentimento já encontrado dentre as composições elegíacas romanas”, segundo McKail, citado por Verducci (1940, p. 289).

\section{Notas}

* Professora Doutora de Língua e Literatura Latina da PUC-Campinas. 


\section{REFERÊNCIAS BiBLIOGRÁFICAS}

BROWNLEE, M. S. The Severed word. Ovid's Heroides and the Novela Sentimental. Princeton: Princeton University Press, 1990.

DELLA CASA, A. Le donne degli elegiaci latini. Torino: Loerscher Editore, 1981.

GAILlARD, J. Limaginaire ludique Ovidien dans les Héroides. In: ThOmAS, J. Les imaginaires des Latins. Perpignan: Presses Universitaires de Perpignan, 1992.

JACOBSON, H. Ovid's "Heroides". Princeton: Princeton University Press, 1974.

KNOX, Peter E. Ovid Heroides. Select Epistles. Cambridge: Cambridge University Press, 1995.

OVIDE. Héroides. Texte établi par Henri Bornecque et traduit par Marcel Prévost. Paris: "Les Belles Lettres", 1965.

PORTE, D. Rome: l'esprit des lettres. Paris: Éditions La Découverte, 1993.

TODOROV, T.; Bakhtin, M. The Dialogical Principle. Trad. Wlad Godzich. Minneapolis: University of Minnesota Press, 1984.

VERDUCCI, F. Ovid's Toyshop of the Heart: Epistulae Heroidum. Princeton: Princeton University Press, 1940.

VAN RAIJ, Cleonice Furtado de Mendonça. Discursive conflict in Ovid's Heroides.

ABSTRACT: The purpose of this article is to analyse, in the Heroides, the discursive conflict between the individual and the universal, revealing how the author of each letter manifests, by means of an internal monologue, her personal world in a dimension that is totally different from the psycological model that it represents.

KEY WORDS: Ovid; Heroides; discursive conflict. 